\title{
Erratum zu: Die Bedeutung von Institutionen für die Weiterbildung Älterer
}

\section{Erratum zu: \\ V. Philipps, Die Bedeutung von Institutionen für die Weiterbil- dung Älterer, https://doi.org/10.1007/978-3-658-28004-8}

Die Originalversion dieses Buches enthält leider keine Anhänge.

Die fehlenden Anhänge B, C und D sind jetzt in den jeweiligen Kapiteln verlinkt und das untenstehende Material ist jetzt online verfügbar.

Anhang B: Ergänzende Online-Tabellen:

Kapitel 4

Kapitel 5

Kapitel 6

Kapitel 7

Anhang C: Datengrundlage und Methoden:

Kapitel 5

Anhang D: Robustheitstests für die Kalibrierung:

Kapitel 7

Die korrigierten Versionen der Kapitel sind verfügbar unter https://doi.org/10.1007/978-3-658-28004-8_4 https://doi.org/10.1007/978-3-658-28004-8_5 https://doi.org/10.1007/978-3-658-28004-8_6 https://doi.org/10.1007/978-3-658-28004-8_7 